\title{
Rat study sparks GM furore
}

\section{Cancer claims put herbicide-resistant transgenic maize in the spotlight.}

\section{BY DECLAN BUTLER}

$\mathrm{E}$ urope has never been particularly fond of genetically modified (GM) foods, but a startling research paper published last week looks set to harden public and political opposition even further, despite a torrent of scepticism from scientists about the work.

The study ${ }^{1}$, published in the peer-reviewed journal Food and Chemical Toxicology, looked for adverse health effects in rats fed NK603 maize (corn), developed by biotech company Monsanto to resist the herbicide glyphosate and approved for animal and human consumption in the European Union, United States and other countries. It reported that the rats developed higher levels of cancers, had larger cancerous tumours and died earlier than controls. The researchers have not conclusively identified a mechanism for the effect.

The rats were monitored for two years (almost their whole lifespan), making this the first long-term study of maize containing these specific genes. About a dozen longterm studies of different GM crops have failed to find such stark health

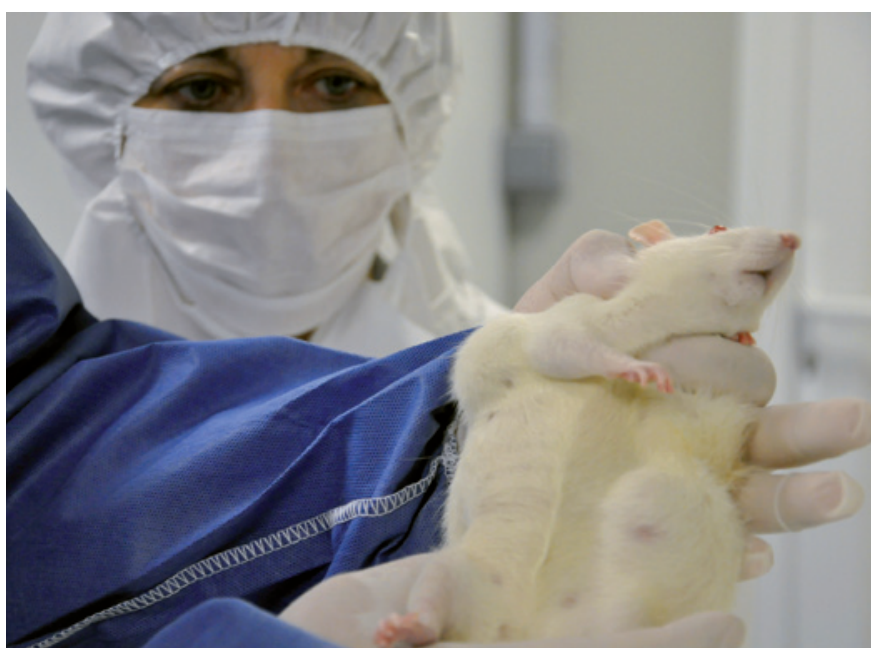

Tumours developed more readily in rats fed genetically modified maize than in controls, recent research reports. effects $^{2}$. An earlier test of NK603 maize in rats in a 90-day feeding trial - the current regulatory norm - sponsored by Monsanto showed no adverse effects ${ }^{3}$.

The explosion of media coverage about the findings has energized opponents of GM food, especially in Europe. French Prime Minister Jean-Marc Ayrault said that, if the results are confirmed, the government will press for a Europe-wide ban on the maize. The European Commission has instructed the independent European Food Safety Agency (EFSA) in Parma, Italy, to assess the study.

Many scientists, however, have already questioned the study's methodology and findings. They assert that the data presented in the paper do not readily allow the claims to be independently assessed, and they question the study's experimental design and its statistical analysis of any differences between the treated groups and controls. Other scientists point out that the Sprague-Dawley strain of rats used in the experiments has been shown to be susceptible to developing tumours spontaneously, particularly as they grow older, making it difficult to interpret the results. Monsanto itself said that the study "does not meet minimum acceptable standards for this type of scientific research".

The €3.2-million (US\$4.1-million) study was led by Gilles-Eric Séralini, a molecular biologist at the University of Caen, France, in collaboration with the Paris-based Committee for Research and Independent Information on Genetic Engineering (CRIIGEN), whose scientific board he heads. CRIIGEN bills itself as

as

an "independent non-profit organization of scientific counter-expertise to study GMOs, pesticides and impacts of pollutants on health and environment, and to develop non polluting alternatives". The article's publication coincides with the launch this week of a book by Séralini, Tous Cobayes? (All of Us GuineaPigs Now?), which tells the story of the research project and is accompanied by a film and a television documentary.

In a written response to Nature's questions, Séralini and Joël Spiroux de Vendômois, president of CRIIGEN and a co-author of the paper, say that they have been surprised by the "violence" and immediacy of scientists' criticisms. They argue that most of the critics are not toxicologists, and suggest that some may have competing interests, including working to develop transgenic crops. They also point out some errors by critics, such as claims that graphs in the paper showing rat survival over time do not include data for the controls.

The authors concede that Sprague-Dawley rats may not be the best model for such longterm studies, but argue that the difference between the NK603-fed rats and controls is

marked, and that many fewer control rats developed tumours in middle age. The 90-day trial of Monsanto's NK603 maize used in its authorization also used Sprague-Dawley rats, they add.

José Domingo, a toxicologist at Rovira i Virgili University in Reus, Spain, and a managing editor of Food and Chemical Toxicology, says that the study raised no red flags during peer review. Domingo, who last year authored a critical review of safety assessments of GM plants ${ }^{4}$, has previously complained about the lack of independent feeding studies of GM foods.

The controversy over the findings is likely to be settled only after detailed analysis of the paper and its data, and replication of the experiments. But Séralini says he won't release his data until the raw data underpinning the authorization of NK603 in Europe are also made public. And he wants all the data to be assessed by an independent international committee, arguing that experts involved in the authorization of the maize should not be involved. EFSA chief Catherine Geslain-Lanéelle disagreed, and said that her agency is well placed to assemble a multidisciplinary group to give an impartial assessment.

Some scientists, however, have long questioned whether such feeding studies are appropriate for testing the safety of whole foods, says Peter Kearns, head of food safety, nanosafety and chemical accidents for the Organisation for Economic Co-operation and Development in Paris. They were designed for testing chemicals where precise doses of purified and well-characterized compounds can be administered, whereas compounds in foods are heterogeneous, and doses are difficult to control. Regulators rely mainly on more robust tests that compare the toxicological and nutritional profiles of GM foods with their non-GM counterparts to screen for potential concerns.

Resolution of the debate over the safety of GM foods can come only from rigorous science clarifying the issues, Kearns adds. SEE EDITORIAL P.474

1. Séralini, G.-E. et al. Food Chem. Toxicol. http://dx.doi. org/10.1016/j.fct.2012.08.005 (2012).

2. Snell, C. et al. Food Chem. Toxicol. 50, 1134-1148 (2012).

3. Hammond, B., Dudek, R., Lemen, J. \& Nemeth, M. Food Chem. Toxicol. 42, 1003-1014 (2004).

4. Domingo, J. L. \& Giné Bordonaba, J. Environ. Int. 37, 734-742 (2011). 